\title{
VENOUS PRESSURE AND OCULAR TENSION* DATA CONCERNING THE DIURNAL VARIATION OF OCULAR TENSION
}

\author{
BY

\section{PAUL WEINSTEIN AND JOSEPH FORGÁCS} \\ Budapest, Hungary
}

ATTENTION was first called to the diurnal changes of ocular tension by Maslenikow (1904). The aetiology of this physiological phenomenon is controversial. Köllner (1918) associated it with the arterial system, assuming that a sudden rise or fall in blood-pressure causes a corresponding change in ocular tension. But the diurnal variation of ocular tension cannot be related to blood-pressure, because the former is highest in the morning when the latter is lowest. Thomassen and others (1950) stated that a variation in the pressure in the episcleral veins precedes the diurnal variation of the ocular tension. Weinstein $(1950,1951)$ has demonstrated that pressure on the jugular vein holds up the circulation within the aqueous veins.

At the Ophthalmic Department of the Szabolcs State Hospital, Budapest, we have investigated a possible co-ordination of the general venous pressure and the diurnal variation of the ocular tension, determining the former by the method of Groák (1938) on the cubital vein (normally up to $15 \mathrm{~cm}$. water). Ciotola (1936a, b) and Benstein (1950), state that the pressure in the cubital vein is increased in cases of congestive glaucoma, but we were unable to

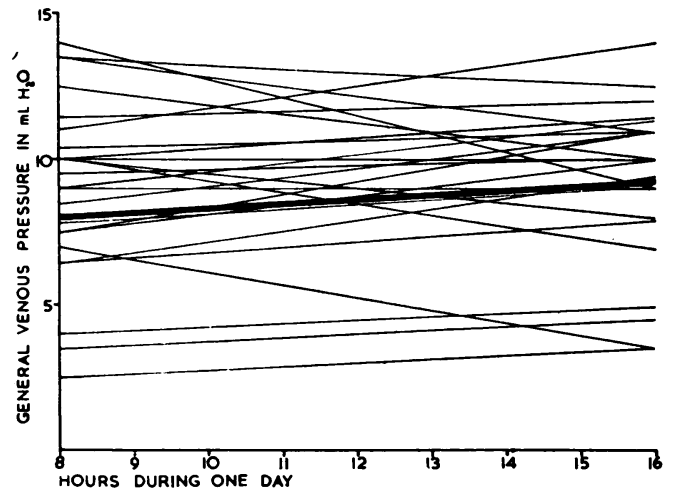

Fig. 1.-Venous pressure in thirty normal cases. Heavy line shows average. confirm this statement by single determinations of the venous pressure. The existence of diurnal changes in the venous pressure is well established by Gönczy and others (1930), Burch (1950), and Benstein (1950). The difference may amount to several centimetres of water, the pressure generally being lower in the morning than at any other time of the day (Fig. 1). Our own investigation revealed that the process of filling up an aqueous vein is concomitant with a variation in the pressure within the cubital vein (Fig. 2, opposite). According to Thomassen and others (1950), variations in the aqueous vein pressure reflect corresponding changes in ocular tension.

\footnotetext{
* Received for publication February 2, 1953
} 


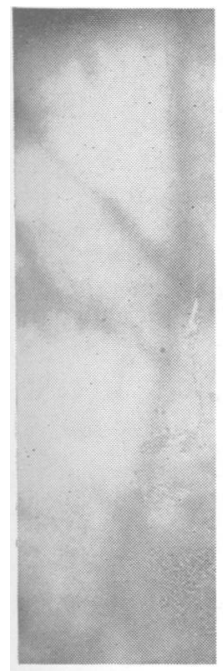

(a)

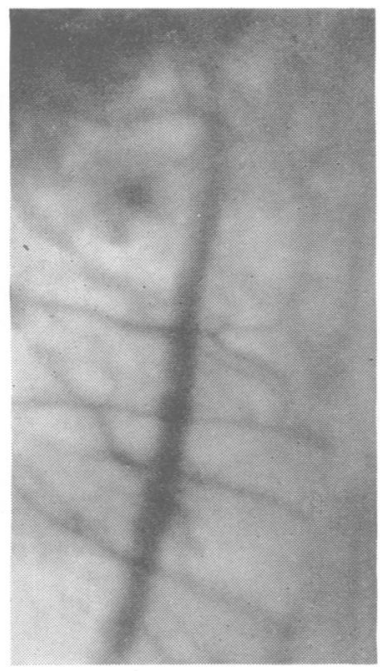

(b)

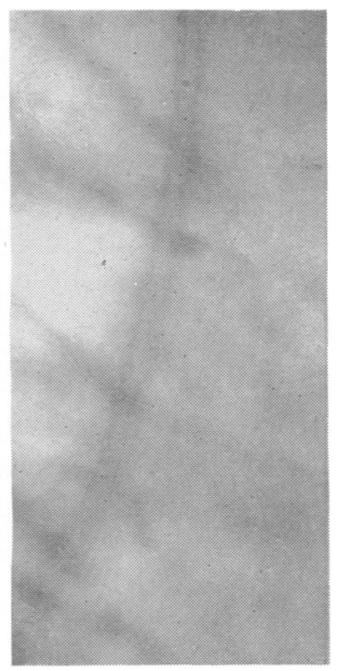

FIg. 2.-(a) Aqueous vein full of a queous, general venous pressure 2.5 ml. $\mathrm{H}_{2} \mathrm{O}$.

(b) Same vein full of blood, general venous pressure 4.5 ml. $\mathrm{H}_{2} \mathrm{O}$.

(c) Same vein laminated, general venous pressure 3.0 ml. $\mathrm{H}_{2} \mathrm{O}$.

On this point, we did not find, in every case, a close relation between the filling of the episcleral veins and the general venous pressure. According to the recent investigations of Fritz (1951), the local tonicity of the precapillary arterioles significantly affects the ocular tension, and our own experiments were based on this assumption. Former investigators (Mészáros and Toth, 1933; Weinstein, 1950, 1951), have shown that reactive hyperaemia of dermal capillaries following the removal of a tourniquet from the finger is considerably delayed in glaucomatous patients. The present investigation disclosed that the hyperaemia of the dermal capillaries of the finger of normal individuals likewise shows diurnal changes, but without a set pattern.

It is the opinion of Benstein (1950) that, whereas venous pressure is lowest in the morning in normal persons, it is highest at that time in sufferers from congestive glaucoma: i.e. that the rhythm is inverted in such cases. Our own observations suggest the same conclusion (Fig. 3).

These facts indicate that variations in the ocular tension are related to pressure changes in the intra-ocular capillaries and veins, which according to recent data (Duke-Elder, 1952 ; Magitot,

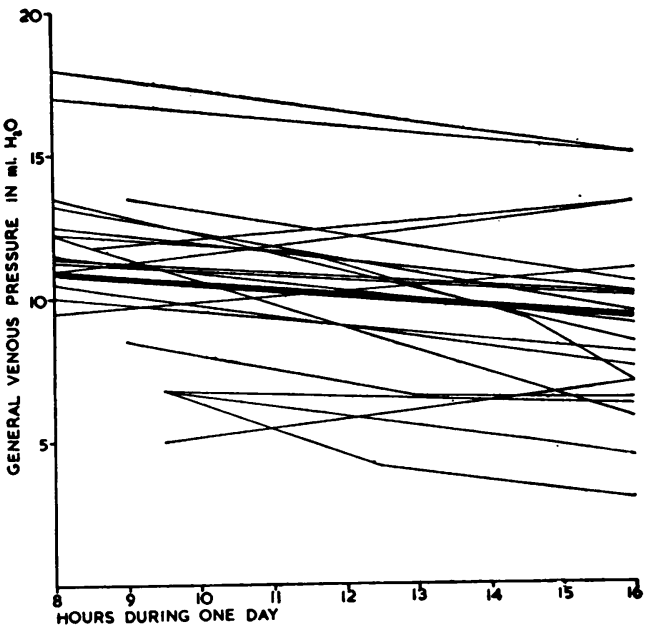

Fig. 3.-General venous pressure in twentyfive glaucomatous patients. Heavy line shows average. 
1952; Weinstein, 1951), are subject to the influence of (the central nervous system. If the increase of the arterial and venous pressure is concomitant with the filling of the intraocular capillaries, the ocular tension is furthero increased.

\section{Summary}

The pressure of the cubital vein demonstrates a characteristic diurna $\frac{\sqrt{m}}{0}$ variation (being generally lower in the morning), which is concomitant ino the majority of cases with the filling of the episcleral aqueous veins. In casesof glaucoma the venous pressure is higher in the morning.

Reactive hyperaemia of the dermal capillaries of the fingers changes during $\vec{\omega}$ the day, and this change suggests a corresponding change in the intra-ocularo. capillaries.

These diurnal changes of rhythm are controlled by the central nervousi system.

\section{REFERENCES}

Benstein, I. U. (1950). Vestn. Oftal., 29, No. 5, p. 21.

BURCH, G. E. (1950). "A Primer of Venous Pressure ", p. 119. Lea and Febiger, Philadelphia. CiotolA, G. (1936a). Z Zbl. ges. Ophthal., 37, 35. (1936b). Rass. ital. Ottal., 5, 82.

DUKe-ELDER, S. (1952). Amer. J. Ophthal., 35, 1.

FrITZ, A. (1951). "XVI Concilium Ophthalmologicum, 1950. Britannia Acta ", vol. 1, p. 1250

GöNCZY, V. I., KISS, J., and ENYEDY, Z. (1930). Orv. Hetil., 74, 287 (also in Z. ges. exp. Med 70, 236). (1930).

Groák, B. (1938). Dtsch. Arch. klin, Med., 181, 579.

KölLNER (1918). Münch. med. Wschr., 65, 229.

Magitot, A. (1952). Ann. Oculist., Paris, 185, 422.

MASLENIKOW, J. (1904). Vestn. Oftal., 21, 237.

MésZÁros, K., and Toth, Z. (1953). Klin. Mbl. Augenheilk., 90, 67.

Thomassen, T. L., Perkins, E. S., and Dobree, J. H. (1950). British Journal of Ophthalmology? 34, 221 .

WeinsteIn, P. (1950). Ibid., 34, 161.

(1951). Orv. Hetil., 92, 1233. 